\title{
Effect of Insulin Transferrin Selenium Administration on Rat's Cultured In Vitro Embryo Post Warming After being Frozen using Vitrification Method
}

\author{
Widjiati $^{1}$, Epy Muhammad Luqman ${ }^{1}$, Viski Fitri Hendrawan ${ }^{2}$, Portia Sumarsono $^{1}$ \\ ${ }^{1}$ Faculty of Veterinary Medicine Airlangga University, Surabaya \\ ${ }^{2}$ Faculty of Veterinary Medicine Brawijaya University, Malang
}

\author{
Kampus C Unair, Jalan Mulyorejo Surabaya \\ Tlp : 031-599278, Fax : 031-5993015 \\ Email: widjiati1962@gmail.com
}

\begin{abstract}
Success of embryo transfer is determined by availability of a plenty of amount of embryo stock. To make embryo stock remain in good quality, it is necessary to have an easy, cheap, simple and effective storage method. One of the storage methods is vitrification.Success of vitrification method is still disrupted due to decreased embryo quality post warming. Decreased embryo viability influences high implantation rate and gestation. Low implantation rate will result in low gestation rate. Therefore, study is needed to optimize vitrification medium so that it will be able to optimize cryoprotectant role to protect embryo due to temperature stressor in vitrification method.Administering Insulin Transferrin Selenium on vitrification medium is able to bind free radicals caused by temperature stressor due to frozen Insulin Transferrin Selenium which is a complex protein that is able to stimulate cell growth, prevent cell damage due to anti oxidant role in it so that it is able to maintain embryo viability post thowing. Insulin Transferrin Selenium is able to increase quality and viability of blastocyst resulted from in vitro culture.The study aims to prove Insulin Transferrin Selenium supplementation on vitrification medium is able to increase viability of rat embryo post warming. Steps of the research cover oocyte collection, embryo vitrification, warming, and in vitro culture. In vitro culture yields morula embryo with excellent quality and fits to be frozen using vitrification method.Insulin Transferin Selenium administration of 5,10 and $15 \mu \mathrm{g} / \mathrm{ml}$ is able to increase embryo viability up to $100 \%$. Frozen embryo post warming and recultured for 5 hours, viability of morula embryo ofthe treatment group administered by Insulin Transferrin Selenium reached $73.4 \%-83.4 \%$ whereas control group without being administered by InsulinTransferrin Selenium reached only $64.7 \%$. The research concludes that Insulin Transferrin Selenium.administration is able to increase viability of rat embryo at morula stage.
\end{abstract}

Key words : vitrification, warming, morula, Insulin Transferrin Selenium 


\section{INTRODUCTION}

Embryo bank is a seri of technological activity that helps reproduction.In vitro fertilization process yields a great deal of embryos and similar embryo age. Excessive embryos after being transferred can be stored by freezing them. Embryos stored frozen can be used as embryo bank and any time they can be warmed before being transferred to a recipient.Many methods are used to freeze embryos and one of them is vitrification.

Method to store embryos mostly used nowadays is vitrification. Vitrification method is a method where a material going to be frozen is put in hiperosmolarity media or cryoprotectant media with high concentration. After that the material is directly dipped in liquid nitrogen so that the frozen solution looks like glass. Technically, the method is able to decrease damaged embryo cells due to freezing. In addition, vitrification method is able to reduce damaged embryos due to freezing as critical temperature can be exceeded quickly (Wilding et al., 2010; Turathum et al., 2010).

Success of vitrification method is still disrupted as quality of embryo post warming decreses (Amir et al., 2013). Decreased embryo quality post warming highly influences embryo implantation rate which in turn will decrease gestation rate. Therefore, study is needed to optimize vitrification medium, so that it can optimize cryoprotectant role to protect embryo due to temperature stressor in vitrification method.

Insulin Transferrin Selenium administration on vitrification medium is able to bind free radicals due to temperature stressor in freezing (Younis et al., 1998). Insulin Transferrin Selenium is a complex protein which is able to stimulate cell growth, prevent cell damage due to role of anti oxidant in it so that it can maintain embryo viability post thawing.According to et al., (2007) and Amir et al., (2013), Insulin Transferrin Selenium is able to increase quality and viability of blastocyst resulted from in vitro culture.

Based on the background above, it is necessary to conduct a research to prove effectiveness.of Insulin Transferrin Selenium on embryo quality post warming.

\section{MATERIALS AND RESEARCH METHODOLOGY}

\section{Materials and Equipments}

Materials used in the research were a male rat of 5 months old, a female rat of 3 months old and liquid $\mathrm{N}_{2}$, Insulin Transferring Selenium (ITS), Pregnant Made Serum Gonodotropin Human Chorionic Gonadotropin (PMSG), Phosphate Buffer Saline (HCG), medium Engle Minimum (MEM), Ethilen Glicol, Sucrose, Bovine Serum Albumin (BSA), mineral oil, gentamysin sulfat, $\mathrm{CO}_{2}$

Equipments used in the research were $\mathrm{CO}_{2}$ incubator, liquid $\mathrm{N}_{2}$ container, inverted microscope, syringe, pasteur pippet, hemi straw, dispossable petridish, and millipore

\section{Research Methodology}

\section{Superovulation and ovum collection}

Female rat was injected with hormone of Pregnant Made Serum Gonadotropin (PMSG atau Foligon) with a dosage of 5 IU. Forty eight hours later it was injected 
with hormone of Human Chlorionic Gonadotropin Human Chorionic Gonadotropin (HCG or Chorulon) and directly mated with male rat which was castrated monomattingly. 17 hours after the female rate was mated, examination of vagina plug was conducted. Next, ovum collection was done on the female rat with its vagina positively plugged. Then, the female rat with its vagina plugged was decapitated, cut and its fallopian tube was taken out. After that, the falopian tube was washed with solution of Phosphate Buffer Saline, next it was moved to petridish and flushed under inverted microscope by ripping fertilization pouch. Finally flushed ovum was washed and prepared for in vitro fertilization.

\section{In vitro Fertilization}

Ovum collected was washed respectively 3 times on media of PBS and MEM. The washed ovum was then moved to fertilization medium while waiting for spermatozoa prepared for in vitro fertilization. Spermatozoa was taken from cauda epididyimis of male rat, and soaked in fertilization with ovum in it . Ovum which was mixed with spermatozoa was then incubated in $\mathrm{CO}_{2}$ incubator $5 \%$ at the temperature of $37^{\circ} \mathrm{C}$ for 7 hours, Then granulosa cells were eroded to observe $2 \mathrm{pn}$.

\section{Embryo culture until morula stage}

After 2 pn was formed, zygote next was moved to culture medium and incubated in $\mathrm{CO}_{2}$ incubator $5 \%$ at the temperature of $37^{\circ} \mathrm{C}$. Culture medium was changed once in two days until embryo reached morula stage.

\section{Modification of vitrificafion medium with supplementation of Insulin Transferrin Selenium (ITS)}

Composition of vitrification medium consists of Phosphate Buffer Saline (PBS) added with intracelular cryoprotectant of Ethilen Glicol (EG) $30 \%$ and Sucrose 1 M. Modification of vitrification medium was done by adding Insulin Transferrin Selenium with a dosage of $5 \mu \mathrm{g} / \mathrm{ml}, 10 \mu \mathrm{g} / \mathrm{ml}$ and $15 \mu \mathrm{g} / \mathrm{ml}$ (Jeong et al., 2008; Kisiday et al., 2005). Totally the research used 4 groups :

Control Group (C) : PBS + EG $30 \%+$ Sucrose $1 \mathrm{M}$

Treatment Group 1 (T1): PBS + EG $30 \%+$ Sucrose $1 \mathrm{M}+$ ITS $5 \mu \mathrm{g} / \mathrm{ml}$

Treatment Group 1 (T2) : PBS + EG $30 \%+$ Sucrose $1 \mathrm{M}+$ ITS $10 \mu \mathrm{g} / \mathrm{ml}$

Treatment Group 1 (T3) : PBS + EG $30 \%+$ Sucrose $1 \mathrm{M}+$ ITS $15 \mu \mathrm{g} / \mathrm{ml}$

\section{Embryo Vitrification with hemi straw}

Embryo was exposed by vitrification medium consisting of media of PBS, cryoprotectant ethilen glicol, sucrose dan Insulin Transferrin Selenium, next it was put at the tip of hemi straw. The hemi straw which was exposed by liquid $\mathrm{N}_{2}$ was dipped in big straw. When putting hemi straw in big straw, it had to be done in liquid $\mathrm{N}_{2}$ so that the embryo on the tip of hemi straw was not gone, then tip of big straw was fixated and put into cassette straw. After that, the cassette was put into goblet of liquid $\mathrm{N}_{2}$ container.

6. Warming and in vitro embryo culture after. being frozen

Before warming, warm warming medium consisting of Medium 1 (medium PBS + Sucrose 0,5 M), Medium 2 (medium PBS + Sucrose $1 \mathrm{M}$ ) for 15 minutes. Embryo post warming was put into medium 1 for 2.5 minutes, then it was moved to medium 
2 for 7.5 minutes. After that embryo was cultured for 5 hours to see viability of embryo at morula stage.

\section{RESULT AND DISCUSSION}

The number of oocytes which was fertilized in vitro and developed to be zygote was very high that is $100 \%$. Also, percentage of embryo development to be 2 cells, 4 cells, 8 cells, morula was high, it shows that embryo resulted from in vitro fertilization did not have problem. Evaluation on embryos from in vitro culture all show quality with excellent evaluation meaning that there were no flaws on blastomere cells and embryos resulted were good and fitted for being frozen using vitrification method. It can be seen at table 1 and figure 1 below in detail.

Table 1. Data on percentage of oocytes number fertilized in vitro and quality of embryo from in vitro culture

\begin{tabular}{|c|c|c|c|c|c|c|}
\hline Group & number of in & \multicolumn{5}{|c|}{ Observation on embryo growth } \\
\cline { 2 - 6 } & $\begin{array}{l}\text { vitro } \\
\text { fertilized } \\
\text { oocytes }\end{array}$ & 1 cell & 2 Cells & 4 cells & 8 cells & Morula \\
\hline Control & 50 oocytes & $\begin{array}{c}50 \\
(100 \\
\end{array}$ & $\begin{array}{c}45 \\
(90 \%)\end{array}$ & $\begin{array}{c}40 \\
(88.8 \%)\end{array}$ & $\begin{array}{c}36 \\
(90 \%)\end{array}$ & $\begin{array}{c}34 \\
(94.4 \%)\end{array}$ \\
\hline P1 & 50 oocytes & $\begin{array}{c}50 \\
(100 \%)\end{array}$ & $\begin{array}{c}46 \\
(92 \%)\end{array}$ & $\begin{array}{c}40 \\
(70 \%)\end{array}$ & $\begin{array}{c}38 \\
(95 \%)\end{array}$ & $\begin{array}{c}38 \\
(100 \%)\end{array}$ \\
\hline P2 & 50 oocytes & $\begin{array}{c}50 \\
(100 \%)\end{array}$ & $\begin{array}{c}43 \\
(86 \%)\end{array}$ & $\begin{array}{c}40 \\
(87 \%)\end{array}$ & $\begin{array}{c}37 \\
(92,5 \%)\end{array}$ & $\begin{array}{c}37 \\
(100 \%)\end{array}$ \\
\hline P3 & 50 oocytes & $\begin{array}{c}50 \\
(100\end{array}$ & $\begin{array}{c}40 \\
(80 \%)\end{array}$ & $\begin{array}{c}38 \\
(95 \%)\end{array}$ & $\begin{array}{c}36 \\
(94.7 \%)\end{array}$ & $\begin{array}{c}36 \\
(100 \%)\end{array}$ \\
& & & & & & \\
\hline
\end{tabular}




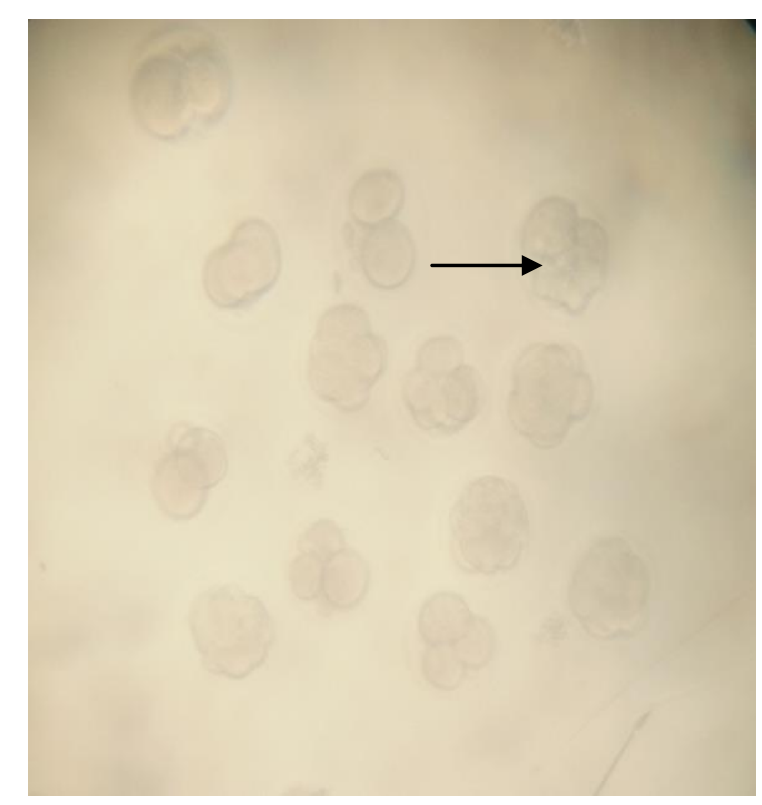

Figure 1. Rat embryo at morula (stage $\longrightarrow$. result of in vitro culture

Percentage on evaluation of fragmentation number or embryo death post warming at control groups and administered with Insulin Transferrin Selenium was high enough that is around $33 \%$ compared to groups administered with Insulin Transferrin Selenium decreased around 16.6 -26.6\%. Evaluation result on embryo after being frozen using vitrification method shows that administering Insulin Transferrin Selenium, vitrification medium is able to increase viability of embryo after being frozen. It can be seen at the following table.

Table 2. Data on percentage of embryo quality after one week vitrification and post warming

\begin{tabular}{|c|c|c|c|c|}
\hline Group & $\begin{array}{l}\text { Number of } \\
\text { morula }\end{array}$ & $\begin{array}{l}\text { number of } \\
\text { vitrified } \\
\text { embryo }\end{array}$ & \multicolumn{2}{|l|}{ post thawing evaluation } \\
\hline & & & dead(degenerated) & live \\
\hline Control & 30 & 30 & $10(33.3 \%)$ & $10(64.7 \%)$ \\
\hline P1 & 30 & 30 & $8(26.6 \%)$ & $15(73.4 \%)$ \\
\hline P2 & 30 & 30 & $5(16.6 \%)$ & $17(83.4 \%)$ \\
\hline P3 & 30 & 30 & $5(16.6 \%)$ & $18(83.4 \%)$ \\
\hline
\end{tabular}




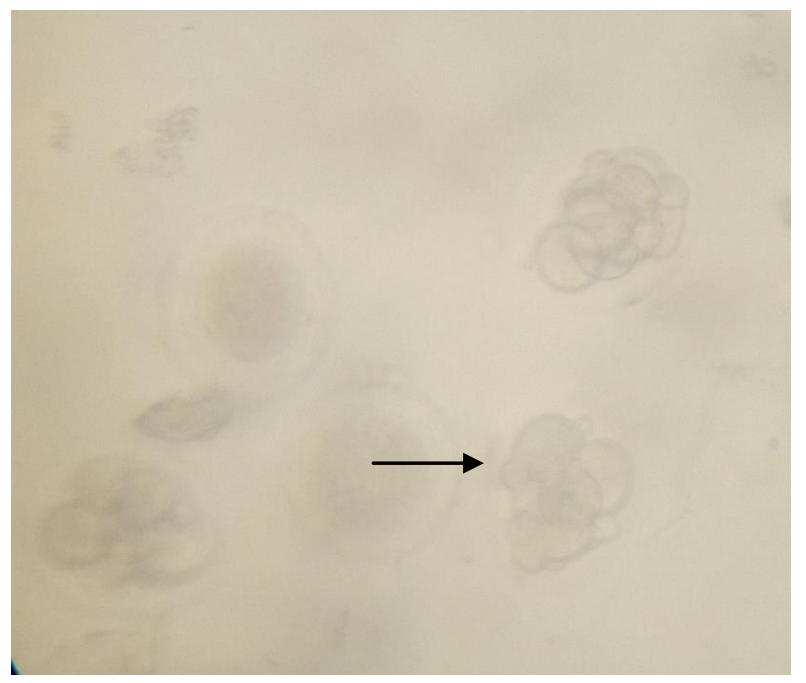

Figure 2. Fragmentation embryo post thawing

Drastic change at temperature will happen at vitrification process, so that cells are damaged, cells, therefore are not able to protect themselves from Reactive Oxygen Species (ROS) (Choi et al., 2009). According to Widjiati dkk (2011) production of Reactive Oxygen Species (ROS) in vitrification process often can lead to decreased embryo viability post warming so that an anti oxidant compound in vitrification process is able to combat negative effects when ROS is formed in the cell due to metabolic activity. Therefore, study is needed to optimize vitrification medium so that cryoprotectant role can be optimized to protect embryo due to temperature stressor in vitrification method.

Administering Insulin Transfferin Selenium in culture medium is able to pretect the embryo from negative efects due to ROS in the cell (Das et al., 2013). Insulin Transferrin Selenium is complex media supplements consisting of compounds of insulin, transferrin, dan selenium (Liu et al., 2014). Insulin Transferrin Selenium is complex protein which is able to stimulate cell growth, prevent cell damage due to anti oxidant role in it so that it can maintain embryo viability post warming. According to Qin et al., (2007) and Amir et al., (2013), Insulin Transferrin Selenium is able to increase quality and viability of blastocyst resulted from in vitro culture.

\section{CONCLUSION}

Based on the research conducted, it can be concluded that administering Insulin Transferrin Selenium on vitrification medium is able to increase embryo viability post warming.

\section{References}

Amir, G., B. Rubinsky,Y. Kassif, L.Horowitz, A.K. Smolinsky and J.Lavee. 2013. Preservation of myocyte structure and mitochondrial integrity in subzero cryopreservation of mammalian hearts for transplantation using antifreeze 
proteins-an electron microscopy study .European J. Cardio-Thoracic Surg. 24(2) : 292-297.

Choi, K., J. Kim, W. Gyung, Kim dan C. Chulhee. 2009. Oxidative stress-induced necrotic cell death via mitochondira-dependent burst of reactive oxygen species. Current Neurovascular Research 6 (4) : 213-222.

Das, Z. C, M. K. Gupta, S. J. Uhm and H. T. Lee. 2013. Supplementation of insulin- transferrin- selenium to embryo culture medium improves the in vitro development of pig embryos. Cambridge Journals Online (Abstract) $18: 1-8$.

Jeong.Y.W, M.S.Hossein, D.P.Bhandari, Y.W.Kim, J.H.Kim, S.W.Park, E.Lee, S.M.Park, Y.I.Jeong, J.Y.Lee, S.Kim and W.S.Hwang. 2008. Effect insulin transferrin selenium in defined and porcine follicular fluid supplemented IVM media on porcine IVF and SCNT embryo production. J. Anim. Reprod. Sci 106 : 13-24

Kisiday.J.D., B.Kurz, M.A.Dimicco and A.J.Grozinsky. 2005. Evaluation of medium supplemented with insulin transferrin selenium for culture of primary bovine calf chondrocytes in three-dimensional hydrogel scaffolds. J. Tissue Engineering. 11 (1-2) : 141-151

Liu, X., J. Liu, N. Kang, L. Yan, Q. Wang, X. Fu, Y. Zhang, R. Xiao, and Y. Cao. 2014. Role of insulin transferrin selenium in auricular chondrocyteproliferation and engineered cartilage formation in vitro. International Journal of Molecular Sciences $15: 1525-1537$.

Qin H, Tianxin Yu, Tingting Qing, Yanxia Liu, Yang Zhao, Jun Cai,Jian Li, Zhihua Song, Xiuxia Qu, Peng Zhou, Jiong Wu,Mingxiao Ding, ${ }^{1}$ and Hongkui Deng. 2007. Regulation of Apoptosis and Differentiation by p53 in Human Embryonic Stem Cells. J. Biol. Chem, 282: 5842-5852.

Turathum B., K. Saikhun, P. Sangsuwan and Y. Kitiyanant. 2010. Effects of vitrification on nuclear maturation, ultrastructural changes and gene expression of canine oocytes. J.Reprod Biol Endocrinol. 2010; 8: 70.

Widjiati, A. W. Ratri, dan M. Z. Arifin. 2011. Pengaruh berbagai konsentrasi krioprotektan propanediol pada proses vitrifikasi terhadap viabilitas embrio mencit pasca thawing. Veterinaria 4 (2).

Wilding M.G, C. Capobianco, N. Montanaro, G. Kabili, L. Di Matteo,E. Fusco and B. Dale. 2010 Human cleavage-stage embryo vitrification is comparable to slowrate cryopreservation in cycles of assisted reproduction. J Assist Reprod Genet. 27(9-10): 549- 554.

Younis.A.I., B. Rooks, S. Khan and K.G. Gould. 1998. The effect of antifreeze peptide III (AFP) and insulin transferrin selenium (ITS) on cryopreservation of chimpanzee (Pan trogodytes) spermatozoa. J. of Andrology. 19 (2) : 207- 214 